\title{
FEDERALISMO E MUTAÇÕES CONSTITUCIONAIS
}

\section{FEDERALISM AND INFORMAL CONSTITUTIONAL CHANGES}

José Adércio Leite Sampaio ${ }^{1}$

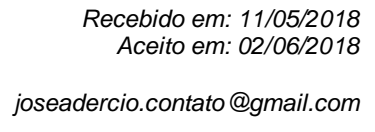

Resumo: Os processos informais de mudança da Constituição, também conhecidos como "mutações constitucionais", ocorreram em diversos Estados federais como uma alternativa às reformas previstas nas normas constitucionais. Por meio deles, altera-se o sentido de enunciados da Constituição sem modificar seu texto. Essas mudanças informais, além de discussões de legitimidade democrática, trazem sérios problemas às exigências de rigidez constitucional e de participação das entidades subnacionais nos processos deliberativos federais, especialmente para promover emendas ou revisão à Constituição.

Palavras-chave: Processos informais de mudança constitucional. Estado federal. Rigidez constitucional.

\begin{abstract}
Informal processes of constitutional change, also known as "constitutional mutation", have been found in several federal states as an alternative to the reforms envisaged in the constitutional requirements. Through them, it changes the meaning of rules of the Constitution without changing their text. These informal changes, in addition to discussions of democratic legitimacy, bring serious problems to the demands of constitutional rigidity and participation of subnational entities in federal deliberative processes, especially in the case of amendments or revision of the Constitution.
\end{abstract}

Keywords: Informal processes of constitutional change. Federal state. Constitutional rigidity.

\section{INTRODUÇÃO}

Os tipos ou fórmulas do Federalismo giram em torno da coexistência de autogovernos ou autonomias, em nível geral ou nacional e subnacional ou parcial, envolvendo o compartilhamento entre eles de tarefas e recursos, nos termos definidos por meio de uma constituição escrita e rígida (SAMPAIO; PINTO, 2015, p. 69). O Estado federal tem, na Constituição formal, uma de suas premissas. (LENAERTS, 1990, p. 205). É ela que reconhece as autonomias e competências das entidades federativas, bem como os mecanismos de relações entre elas, incluindo os mecanismos de participação das unidades subnacionais nos processos deliberativos federais. (SCELLE, 1944, p. 194; BURDEAU, 1972, p. 51). Entende-se que as mudanças no texto constitucional dependeriam, além de um quórum de aprovação qualificado, da aquiescência dessas unidades, manifestadas pela Casa Alta e, o que seria mais consentâneo com a ideia de federação, por meio de referendos popular ou das Assembleias subnacionais. (BRYCE, 1891, p. 173; CARRÉ DE MALBERGER, 1948, p. 121-122). Em alguns Estados, a forma federal de Estado é considerada barreira material ou cláusula pétrea, subtraindo-se ao poder de emenda ou revisão constitucionais.

O grande desafio a essa compreensão é dado pela realidade constitucional. Sem modificação no texto, várias Constituições federais passaram por alterações significativas de sentido. As palavras ou orações constitucionais tiveram seu alcance alargado ou reduzido, por meio dos diversos jogos linguísticos de aplicação, tanto da parte do Judiciário, quanto dos atores políticos. (ACKERMAN,

\footnotetext{
${ }^{1}$ Pontifícia Universidade Católica de Minas Gerais - PUCMG - Belo Horizonte - Minas Gerais - Brasil
} 
1991; ESKRIDGE JR.; FEREJOHN, 2001). Esse processo de mudança silenciosa e informais é tanto maior quanto mais antiga for a Constituição. Nos Estados Unidos, por exemplo, tem sido o modo dominante de "atualização constitucional", principalmente mediante a interpretação que os tribunais daquele pais e, em especial, a Suprema Corte dão ao texto da Constituição (DIXON, 2011, p. 339).

Alguns estudiosos chegam a afirmar, no caso dos Estados Unidos, que o processo formal de emenda, se não for irrelevante (STRAUSS, 2001, p. 1460), não é a maneira mais importante de mudança constitucional (STRAUSS, 2010, p. 115; DIXON, 2011, p. 97). Esses processos informais seriam motivados por exigências que decorreriam de alterações importantes da realidade, dos valores e da compreensão social e política tanto de aspectos estruturais e de organização política, quanto do catálogo de direitos fundamentais (ALBERT, 2014, p. 1063). Os obstáculos formais e, por vezes, as "cláusulas de eternidade" cobrariam tempo demasiado para reforma ou gerariam um processo de indecidibilidade, que comprometeria a força normativa do texto constitucional e mesmo a confiança que os cidadãos nele depositam. Em razão disso, os agentes públicos, em respostas a reivindicações práticas ou da sociedade, procuram alternativas aos mecanismos formais de alteração, promovendo-Ihe as mudanças silenciosas (ANDERSON, 2008, p. 59).

Pode-se ver nesse processo, porém, uma forma de fraudar a ideia de rigidez constitucional e de impedir, no caso dos Estados federais, que as unidades subnacionais participassem do processo de mudança, ferindo, a um só tempo, o significado de Constituição formal e o pacto federativo. $O$ império dos fatos ou valores sobre esses compromissos constitucionais é ambíguo, contraditório e complexo. (VEGA, 1985, p. 182). É preciso, portanto, examinar com atenção esse problema. Há uma farta bibliografia produzida sobre o tema em diversos lugares e de algum tempo. A revisão bibliográfica deve conduzir o estudo de feitio dedutivo e por comparações, a iniciar-se pelo fenômeno desses processos informais de mudança, mas comumente conhecidos como mutações constitucionais, revelando, por amostragem, sua ocorrência em diversos sistemas constitucionais e seus efeitos mais diretos sobre a estrutura e o funcionamento dos Estados federais.

\section{O FENÔMENO DA MUTAÇÃO CONSTITUCIONAL}

Dá-se, comumente, o nome de mudanças informais ou mutações constitucionais aos processos de alteração da Constituição que não afetam o texto dos enunciados constitucionais, apenas seu significado². São modificações constitucionais que mantêm intacto o texto, mas se lhe acrescentam ou reduzem o alcance semântico, de modo lento, imperceptível e à margem do processo formal de emenda ou revisão (HESSE, 1983, p. 91-92; DAU-LIN, 1998, p. 30; WHITTINGTON, 1999, p. $5^{3}$ ). Esse processo é caracterizado, normalmente, pela falta de uma

\footnotetext{
${ }^{2}$ A terminologia do fenômeno é variada. No catálogo enumerativo, Anna Cândida Ferraz identificou o emprego de expressões como processos oblíquos (FRANCISCO CAMPOS), não formais (MEIRELLES TEIXEIRA), fáticos (MEROLA CHIERCHIA), revisão informal (CANOTILHO) e mudança material (PINTO FERREIRA), ela mesma preferindo falar em "processos indiretos", "não formais" ou "informais" (FERRAZ, 1986, p. 12). O predomínio no Brasil é, contudo, de "mutação constitucional": (BARROSO, 2009, p. 123; SARLET; MARINONI; MITIDIERO, 2012, p. 147).

${ }^{3}$ Discutível a distinção, empregrada pelo autor, entre interpretação e construção. A primeira busca sentidos identificáveis no texto normativo, desenvolvendo-se de forma evolutiva e permitindo um diálogo entre
} 
consciência ou de intenção da mudança, dada a sua dinâmica de adaptação aos câmbios que sucedem gradualmente na realidade subjacente, podendo ser identificado pelos seguintes critérios principais. Em primeiro lugar, a mudança deve funcionar como uma reordenação das normas constitucionais. Em segundo lugar, essa mudança há de fornecer um guia ou padrão para a conduta futura dos atores políticos. Em terceiro lugar, a mudança, embora operada por processos mais espontâneos que planejados, leva a uma vinculação consciente dos atores políticos. E, em quarto lugar, a mudança deve ser compreendida pelos intérpretes - ou a elite de estudiosos e aplicadores do direito constitucional - como um novo comando da Constituição. (GRIFFIN, 2007, p. 61).

A mutação constitucional é resultado das mudanças nos contextos sociais e políticos, pelas exigências e manifestações da dinâmica do processo existencial de uma comunidade política, viabilizada, sobretudo, pela especificidade da incompletude e abertura semântica das normas constitucionais (JELLINEK, 1991, p. 7-8) e pelo recurso quase inesgotável dos princípios constitucionais que permitem o trânsito de um sentido para outro de um mesmo texto constitucional. (HELLER, 1981, p. 277). Embora a literatura costume apontar, na origem, um divórcio entre a norma positivada e a realidade subjacente, entre direito constitucional escrito e o vigente, entre as relações jurídicas na realidade vital do Estado e o sistema constitucional (DAU-LIN, 1998; BARROSO, 2009, p. 126; SARLET; MARINONI; MITIDIERO, 2012, p. 147), há, na intimidade do processo hermenêutico, releituras dos enunciados normativos que, impulsionadas pelas necessidades fáticas e pelo vigor rejuvenescente dos princípios, revelam sentidos até então não identificados (DWORKIN, 1986, p. 225 ss; 2013, p. 66 ss, 172 ss). O intérprete é, assim, produto do da sua história, do texto que o interpela e do contexto em que vive, e a interpretação a fusão do horizonte do texto e do contexto do intérprete. (GADAMER, 2013, p. 415-416). Há, por isso, quem prefira falar em "desenvolvimento" dos sentidos do texto no tempo e seus novos contextos, em vez de "mutação constitucional", cuja tradição remonta a rupturas ou hiatos de normatividade da Constituição (HÄBERLE, 1974, p. 111 ss, 113; 2003 , p. 69ss, 125, 141). A leitura de textos clássicos sobre o tema revela esse quadro de possibilidade de negação da capacidade da Constituição de manter-se a ordenar a realidade.

Segundo a análise de Dau-Lin (1998, p. 31), haveria quatro tipos de mutação constitucional: (a) as originárias de práticas políticas que se desenvolveriam num ambiente que os formalistas chamariam de lacuna constitucional. Seriam mudanças praeter constitutionem; (b) as derivadas de práticas políticas contrárias aos enunciados constitucionais. Seriam mudanças contra constitutionem; (c) as produzidas pela impossibilidade de exercício das competências estabelecidas pela Constituição, em razão do desuso ou da prática política e das exigências da realidade, ou pelo desuso das competências estabelecidas pela Constituição; e (d) as decorrentes da interpretação dos enunciados constitucionais, dando-Ihes significado distinto do original ${ }^{4}$.

Judiciário e os outros poderes, de modo a criar regras para ação governamental. A segunda considera os princípios políticos fundamentais, ocorre no momento de turbulência ou de desentendimentos e opera no interstício dos significados textualmente identificáveis, de modo que estrutura a futura prática política (WHITTINGTON, 1999, p. 7).

${ }^{4}$ Jellinek também catalogava vários tipos de mutação, levando-se em conta, que a realiza: a) os parlamentares (praxis parlamentares); b) os agentes politicos em geral (prática constitucional ou convenção constitucional) e c) pela jurisdição. Haveria sua ocorrência: a) como consequência de uma necessidade política; b) pelo desuso dos poderes constitucionais; e c) pela necessidade de preenchimento de lacunas. (JELLINEK, 1991, p. 7, 19). 
A mutação do segundo tipo apresenta desafios à teoria da Constituição e a sua ideia de supremacia constitucional e a recorrência de sua referência, notadamente, no Direito Público alemão tem forte raiz nos debates levados a efeito no final do século XIX, sobretudo, diante da inexistência, à época, de um sistema de controle de constitucionalidade e do predomínio do positivismo legalista, cuja lacuna epistemológica e empírica, haveria de ser suprida pelo império dos fatos, pelo fait accompli, o (irracional) fato consumado (KORIOTH, 2000, p. 46). Por isso, os primeiros estudos do assunto, em Laband (1895) e Jellinek (1991[1906]), devem ser considerados nesse contexto, assim como a influência que exerceram sobre alguns weimaristas ou seus observadores como era o caso de Dau-lin (URRUTIA, 2000) ${ }^{5}$. O terceiro tipo pode ou não por em dúvida a validade constitucional, assim como o último tipo é forma mais conhecida e, ao mesmo tempo, é um poderoso instrumento de validação das anteriores, ressalvadas, em princípio, as que forem inconstitucionais.

As mudanças de visões de mundo e de valores ou, por vezes, de relação de força dentro da sociedade conduzem a uma dinâmica distinção de compatibilidade entre norma e realidade normada, sentido normativo e facticidade política. A compreensão desse fenômeno nem sempre é tão simples como aparenta à primeira vista. Apenas em situações limites e na fotografia do complexo fáticonormativo que um dado instante permite ou tira, é de mais fácil elucidação. Há dois extremos no intercâmbio ou tarefa de compatibilidade, um, frontalmente, inconstitucional; outro, claramente constitucional. O domínio da normatividade pelo fático, no primeiro extremo, leva ao desprestígio da força normativa da Constituição. Ao desprestígio ou ao seu fim. A ascensão de Mussolini ao poder da Itália não se fez com revogação formal do Estatuto Albertino. Entretanto, seu governo em nada se adequava às exigências de uma monarquia parlamentar e ao espírito do Estatuto. A Constituição caducava às práticas e leis de um governo fascista. (CRISAFULLI, 1970, p. 116).

Uma realidade que desafie a Constituição pode exigir dela duas respostas jurídicas: o expurgo dessa realidade pela invalidade ou declaração de sua inconstitucionalidade; ou a reforma da Constituição para ajustar-se à nova realidade, desde que obediente ao procedimento de emenda ou revisão. Nas duas hipóteses, tem-se o predomínio da norma constitucional sobre a facticidade violadora de seus quadrantes.

Note-se que a prevalência dos fatos ou a supremacia das normas são, como se disse, extremos que admitem espaços de indefinição entre si. A realidade e a norma não são sempre tão divorciadas que permitam uma das duas saídas. As tarefas de aplicação da norma constitucional não se limitam a exercícios de subsunção formalista. A norma prenuncia e impregna a realidade que visa norma e é definida por essa mesma realidade. (MÜLLER, 1993, p. 212). A construção de sentidos é sempre uma tarefa de acoplamento de realidade e norma que se opera no tempo, a ponto de ser complicado dizer o que é jurídico e o que é extrajurídico, exceto nos extremos de um hiperintérprete que rompe a linha de construção dos sentidos juridicamente possíveis.

\footnotetext{
${ }^{5}$ Sob a Constituição de Weimar, não havia o controle de constitucionalidade, à exceção de três mecanismos: a) o controle de primazia do direito federal sobre o direito dos Länder (art. 13), exercício pelo Tribunal do Reich (Reichgericht); b) o controle de conflitos constitucionais entre órgãos constitucionais, entre o Reich e os Länder ou desses entre si, exercido pelo Tribunal de Estado do Reich Alemão (Staatsgerichthoft des deutches Reichen); e c) o controle difuso pelos juízes do direito pré-constitucional (art. 178.2). Houve, todavia, o reconhecimento de que o juiz poderia também controlar a constitucionalidade das leis posteriores a 1919 numa polêmica decisão do Reichgericht de 5 de novembro de 1925 (HELLER, 1985, p. 288-289; URRUTIA, 2000, p. 115):SSEPE:
} 
A realidade constitucional é o reino das conexões entre direito e política, travejado por aspectos econômicos e sociais. (LUHMANN, 1996). É ela que, ao ser simultaneamente produto e resultado das mediações recíprocas entre normatividade e facticidade, define os sentidos do constitucional e do inválido. A aplicação constitucional é construção normativa e movimento constante de diferenciação entre um e outro sentido, o constitucional e o inconstitucional, a validade e a invalidade. (VEGA, 1985, p. 208, 215). O recurso à principiologia enriquece o debate no esforço de construir coerência do e ao discurso, de modo a evitar a decisão e a ruptura sincrônica e diacrônica do processo argumentativo tanto de justificação quanto de aplicação, da legislação e da jurisdição (HELLER, 1981, p. 277; HABERMAS, 2003, p. 324-325; STRECK; LIMA; OLIVEIRA, 2007, p. 61).

Os jogos de linguagem nem sempre permitem precisar a distinção entre os dois planos, quando se recorre aos princípios que estruturam ou imantam a ordem jurídica com suas pretensões de justiça. A seletividade principiológica pode, em si mesma, ser uma tarefa decisionista, tanto quanto a sua aplicação nas teias retóricas que, pretensamente, constroem-se da práxis intersubjetiva de uma comunidade de intérpretes. A simples referência ao mundo dos princípios, portanto, não fecha as lacunas de alterações substantivas de sentidos normativos nem evita o buraco-negro do decisionismo. O direito é feito de texto e de realidade, cuja reunião se revela no sentido com dupla pretensão, de justiça e de efetividade.

É diante desse cenário que se devem tomar na devida conta as observações de que o intencional hiato entre normatividade e realidade constitucionais, no âmbito do constitucionalismo semântico e nominalista ou simbólico é deliberadamente deixado para que se opere a ruptura, pois se não há sentido normativo pré-dado, apenas uma ilusão semântica, estimulada pela pragmática do poder e do statu quo, todo sentido é possível. (SARTORI, 1962, p. 858; LOEWENSTEIN, 1976, p. 216). Não há, nesse ambiente, mutação constitucional, mas uma Constituição mutante, desformalizada, pela perda de sua capacidade de bloqueio às intenções de permanência da elite no poder, e desmaterializada, pela falta de significado normativo que importe compromissos prévios da práxis política e da dinâmica social; o que, para alguns, soa como a hipertrofia simbólica da Constituição e sua intrínseca "desconstitucionalização fática" ou "concretização desconstitucionalizante”. (NEVES, 1996, p. 323).

\section{A MUTAÇÃO CONSTITUCIONAL COMO UM FENÔMENO TRANSCONSTITUCIONAL}

As mudanças informais da Constituição são identificadas em diversos sistemas constitucionais, sobretudo naqueles mais longevos. Há uma relação direta entre tempo, extensão e dificuldade de emenda da Constituição e essas mudanças. (LUTZ, 1994). Poder-se-ia acrescentar, na mesa relação direta, o descompromisso com a normatividade da Constituição ou falta de cultura constitucional (ZAKARIA, 2003). Esses fatores podem ou não atuar conjuntamente. (ROBERTS, 2009). Nos Estados Unidos, a longevidade, a natureza sintética do texto e um processo complicado de emenda se somam na viabilização do fenômeno. Na Argentina, há uma soma dos elementos, embora incidam em graus diferenciados, inclusive no tempo. (SAGÜES, 2003, p. 204 ss, 257; GARGARELLA, 2004) 
A Constituição estadunidense só foi alterada formalmente vinte e sete vezes desde 1787, tendo ocorrido a última alteração em 1992. (LUTZ, 1994). As mudanças informais, no entanto, são bem mais frequentes, levando alguns autores a dizerem que as disposições do Art. $\mathrm{V}$ seriam irrelevantes como indutoras de alteração constitucional ou do significado que as normas da Constituição apresentam. (ACKERMAN, 1991, p. 266 ss; STRAUSS, 2001, p. 1460). No Canadá, não é diferente. Há muitos meios formais de alteração constitucional, de regra, muito complicados. Essa pluralidade de meios, associada a fatores constitucionais, como o fato de haver uma parte da Constituição codificada, outra parte, esparsa ou mesmo não escrita, dificultando a identificação do status de boa parte das normas jurídicas; e fatores extraconstitucionais ou "políticas megaconstitucionas", como a jurisprudência da Suprema Corte, leis nacionais e provinciais e as convenções constitucionais, tem permitido poucas alterações formais da Constituição. (RUSSEL, 2004, p. 72 ss, 75; ALBERT, 2016).

Na Alemanha, o número de emendas à Constituição é muito inferior às alterações que foram aportadas pela interpretação, sobretudo pela atuação construtiva do Tribunal Constitucional Federal. O rol de direitos sociais, econômicos e culturais, inclusive o direito ao meio ambiente sadio, foi, por exemplo, extraído da cláusula geral do Estado Social (HÄBERLE, 2003, p. 63). A doutrina da eficácia dos direitos fundamentais e o desenvolvimento do princípio da proporcionalidade, elevado à máxima central de todo ordenamento jurídico, são outras construções jurisprudenciais que importaram acréscimos de sentido sem alteração de texto. No âmbito do federalismo, as relações intergovernamentais permitiram a criação de estruturas e de políticas que não tinham previsão expressa na Constituição. Assim também ocorreu a mudança de significado de mandato parlamentar de cargos honoríficos a cargos profissionais, por meio da legislação validada pelo Tribunal Constitucional Federal. O funcionamento parlamentar e relação com o governo sofreram modificações, notadamente com o uso de voto de desconfiança numa situação de legitimidade constitucional limítrofe (HOFFMANN, 2012, p. 331-332, 333).

$\mathrm{Na}$ Argentina, não são muitas as emendas constitucionais, embora costumem ser amplas e profundas. Em meio a diversas suspensões de validade do próprio texto constitucional, de interpretação judicial desse texto e de normas consuetudinárias fundamentais, há, por outro lado, muitas alterações informais (SAGÜES, 2003, p. 204 ss, 257; GARGARELLA, 2004; FERREYRA, 2012, p. 222). Na prática, o processo de revisão formal é também pouco utilizado na Bélgica, mas isso não significa que o texto constitucional se mantenha semanticamente intacto, por três razões básicas.

A primeira tem a ver com aquelas leis, pois, embora sem status constitucional, têm sido utilizadas para promover as sucessivas reformas do Estado, incluindo quase todas as normas relativas à alocação de competências e de recursos financeiros às entidades federadas. Em segundo lugar, como em outros Estados federais, a interpretação dada pelas cortes, notadamente pela Corte de Arbitragem, tem levado à ressignificação de algumas cláusulas constitucionais. Enfim, há diversas revisões implícitas, decorrentes da aprovação das revisões formais. As mudanças no texto de um artigo importam ajuste dos âmbitos de incidência e de sentido de outras normas. (BEHRENDT, 2013, p. 38-39). 
No Brasil, embora seja grande o número de emenda constitucional e relativamente pouco o tempo de vida da Constituição, também são registrados alguns exemplos de mutações constitucionais, especialmente provocadas pela jurisprudência do Supremo Tribunal Federal. Sem qualquer pretensão exaustiva, deve ser lembrada, no âmbito do federalismo, como se verá em seguida, a construção jurisprudencial do princípio da simetria que estabelece um limite implícito ao poder constituinte decorrente; o reconhecimento da eficácia geral e vinculante de suas declarações de inconstitucionalidade no controle concentrado e difuso, bem como da modulação de seus efeitos, antes de haver previsão constitucional ou legal (SAMPAIO, 2002; MENDES, 2004; TALAMINI, 2011); a exigência da fidelidade partidária (BRASIL, 2007a, b e c); a ampliação do conceito de família, de modo a incluir as uniões homoafetivas ${ }^{6}$ (PEDRA, 2012); o enriquecimento da definição de "sexo" como critério de discriminação vedada, originariamente, reduzido ao sentido anátomo-fisiológico, passando a referir-se ao gênero, orientação e identidades sexuais (ÁVILA; RIOS, 2016); e a mudança do status normativo dos tratados internacionais de direitos humanos na ordem jurídica interna (MENDES; VALE, 2008/2009).

\section{MUTAÇÃO CONSTITUCIONAL E FEDERALISMO}

O Estado-federal pressupõe, dentre outros elementos conceituais, a existência de uma Constituição formal que reconheça autonomia e competência às unidades constitutivas, além da participação dessas unidades, por meio de representantes na Casa Alta (Senado ou Conselho), nos processos deliberativos nacionais, inclusive nas reformas à Constituição. (SCELLE, 1944, p. 194; BURDEAU, 1972, p. 51). A mutação constitucional pode comprometer esses pressupostos. Como as mutações constitucionais são alterações silenciosas à Constituição, essa participação fica prejudicada, ainda que se imagine, em algumas circunstâncias, a contribuição dos Estados (ou de alguns deles), no processo. Segurança não há, todavia, pois a falta de institucionalidade e previsão podem levar não apenas a arranjos políticos ad hoc, como também a discriminações de algumas entidades federativas nos processos deliberativos federais. Em segundo lugar, o próprio desenho do federalismo adotado e a repartição de competências podem ser informalmente alterados. O Estado federal dos Estados Unidos nasceu altamente descentralizado. A interpretação que a Suprema Corte daquele país deu às cláusulas das competências federais modificou profundamente essa concepção original, tornando-o um Estado mais centralizado. (SAMPAIO, 2002, p. 599 ss). A doutrina dos poderes implícitos às competências enumeradas e o significado de "comércio interestadual", por exemplo, possibilitaram uma ampliação dos poderes da União. O federalismo dual, de origem, deu lugar a um federalismo, senão cooperativo, ao menos, menos competitivo. (INMAN; RUBINFELD,

\footnotetext{
${ }^{6}$ Esse tema também ocupou a jurisprudência de outros países. Na Espanha, em 2005, reconheceram a união homoafetiva, sob argumento de que a Constituição "a través de una interpretación evolutiva se acomoda a las realidades de la vida moderna como medio para asegurar su propia relevancia y legitimidad”. (ESPANHA, 2005). Assim também nos Estados Unidos, em Obergefell v. Hodges, de 2015 (ESTADOS UNIDOS, 2015).
} 
1997; SCHAPIRO, 20097). Essas mudanças foram promovidas a partir do New Deal como exigência de um Estado mais intervencionista. ${ }^{8}$

O entendimento consolidado, desde aquela época, era de que a União poderia legislar sobre diversas matérias não previstas na Constituição, desde que tivesse conexão com a cláusula do comércio, promoção de direitos civis com base na Emenda XIV (5) e houvesse nítida intenção de promover objetivos nacionais. Chegou-se a aceitar que dispusesse até sobre direitos mínimos que deveriam ser assegurados pelos Estados e Municípios a seus servidores (em Garcia v. San Antonio Metropolitan Transportation Authority: ESTADOS UNIDOS, 1985). Entretanto, os anos 1990 assistiram a uma guinada nessa orientação. O "novo federalismo" estava na vaga que se abria com essas jurisprudências, mesmo que à custa de direitos civis e políticos, procurando retomar as bases de um federalismo centrífugo e menos regulado anterior ao New Deal. (FEREJOHN; WEINGAST, 1997). Em United States v. Lopez de 1995, pela primeira vez desde aquele programa, a Corte impôs limites à competência do Congresso para legislar sobre a cláusula do comércio, ao declarar inconstitucional uma Lei de 1990 (Grun-Free School Zones Act), que proibia a posse de armas próximo a escolas: a lei não demonstrava substancial impacto sobre o comércio interestadual. (ESTADOS UNIDOS, 1995). Em City of Boerne v. Flores, (ESTADOS UNIDOS, 1997, limitou o poder do Congresso para aprovar leis de proteção dos direitos civis, nos termos da Seção 5 da Décima Quarta Emenda, exigindo adoção de "remédios" congruentes e proporcionais à gravidade e frequência das violações de direitos civis reconhecidos pela Corte (BALKIN; LEVINSON, 2001) ${ }^{9}$.

Em diversas oportunidades, a Corte afirmou ainda que os Estados não podiam ser processados, com base em leis federais, por violação de direitos civis. Em Seminole Tribe v. Florida, de 1996, a Corte declarou inconstitucional a obrigatoriedade de os Estados terem de negociar com as comunidades indígenas, sob pena de serem, por elas, processados. (ESTADOS UNIDOS, 1996). A possibilidade de os Estados serem processados também foi considerada inconstitucional no caso de

\footnotetext{
7 Em verdade, os estudiosos dividem em diversas etapas a história do federalismo nos Estados Unidos: a) dualista (1790-1860), descentralizado; b) de transição, com o crescimento gradual do poder central (18601933); c) cooperativo (1933-1964), caracterizado pelo crescimento substancial das competências federais, notadamente pelo desenvolvimento de programas sociais decorrentes da Depressão; d) criativo, marcado pela assunção de um papel direto e active da União nos problemas de governos estaduais e locais (1964 a final dos 1980); e) novo (final dos 1980 aos dias atuais): INMAN; RUBINFELD, 1997, p. 43-44; SCHAPIRO, 2009.

8 Um exemplo é a mudança, em 2000, do "Violent Crime Control and Law Enforcement Act of 1994", destinada a enquadrá-la na cláusula do comércio, de modo a superar a decisão em United States v. Lopez (514 U.S. 549 (1995)), que considerara o texto original da lei, que proibia a venda de armas nas vizinhanças das escolas, inconstitucional por não dizer respeito àquela cláusula: (YOUNG, 2007, p. 459).

${ }^{9}$ Não raramente naquele país, as definições de competências federativas são feitas com a integração da interpretação do legislador com a dos juízes. Não se tomam em conta as normas constitucionais, mas o seu desenvolvimento em leis, especialmente nas "super-leis", para definir ou redefinir as fronteiras de competências. (ESKRIDGE JR.; FEREJOHN, 2001). Gonzales v. Oregon é um exemplo disso. O Estado do Oregon legalizara o suicídio assistido por médico em 1994. Os medicamentos que poderiam ser utilizados no procedimento, no entanto, estavam também sujeitos à regulamentação federal com base da Lei de Substâncias Controladas (CSA). Com base nessa Lei, o procurador-geral dos Estados Unidos os incluiu na lista de drogas proibidas. A Suprema Corte entendeu que a regulamentação do procurador-Geral era inválida, dentre outras razões, porque permitia que a União tratasse de um assunto que estava no âmbito da competência primária dos Estados, a profissão médica (ESTADOS UNIDOS, 2006). A Corte pouco se valeu do texto da Constituição. Seus fundamentos para divisar as fronteiras de competências se limitaram, na verdade, às disposições legais. (YOUNG, 2007, p. 431).
} 
violação à lei federal de proteção aos portadores de necessidades especiais (Board of Trustees of the University of Alabama v. Garrett: ESTADOS UNIDOS, 2001), da violência contra a mulher (United States v. Morrison: ESTADOS UNIDOS, 2000) e de tratamento discriminatório (Alexander v. Sandoval: ESTADOS UNIDOS, 2001).

Os instrumentos de estímulo à cooperação foram também questionados. A competência da União para criar determinada política pública e condicionar o repasse de verba aos Estados para o cumprimento dessa política, mesmo no âmbito das competências estaduais, o chamado "federal spending power" ou "spending clause", havia sido reconhecida em, pelo menos, dois casos Steward Machine Co. v. Davis, de 1937 (ESTADOS UNIDOS, 1937), e South Dakota v. Dole, de 1987. (ESTADOS UNIDOS, 1987). Entretanto, a Corte afirmou que a referida cláusula não podia, entretanto, ser empregada para coagir os Estados a aderir a um programa criado pelo governo federal, embora não tivesse reconhecido essa coação naquelas duas oportunidades, o que levou parte da literatura a afirmar que se tratava de uma proibição teórica ou de mera obiter dictum (HUBERFELD; LEONARD; OUTTERSON, 2013). Em 2012, porém, julgou que a expansão do "Medicaid", promovida pelo "Patient Protection and Affordable Care Act" (mais conhecido como Obamacare), para incluir uma nova categoria de beneficiários excluídos nos anteriores, era inconstitucional, por dar poderes ao Executivo federal de suspender os repasses federais relacionados aos antigos programas de assistência à saúde, se não houvesse adesão ao novo programa. A depender de como esse precedente venha a ser usado, pode comprometer a efetividade de políticas que exijam grau de cooperação entre as unidades federativas (BALKIN; LEVINSON, 2001, p. 1057). O cenário que se desenha, desde então, ainda é incerto, embora se aposte na manutenção das linhas descentralizantes do "novo federalismo". (KAHN, 2013; CONLAN; POSNER, 2016; CONLAN, 2017).

No Canadá, há vários exemplos também de mudanças informais da Constituição. Existe, no Ato Constitucional de 1867, a previsão de que o Executivo provincial pode, alternativamente ao seu poder de sanção, encaminhar projeto de lei, aprovado pelo Legislativo local, para sanção federal. No mesmo dispositivo, admite-se que o Governo federal possa suspender, literalmente, revogar, lei aprovada pelas Províncias. Esses poderes federais, que punham em dúvida a própria natureza federal do Estado, passaram a ser considerados anacrônicos, não sendo utilizados pelos governos ao longo do tempo e tidos como revogados por convenções constitucionais. (HEARD, 1991, p. 105; ALBERT, 2014, p. 660 ss). Diversas decisões judiciais sobre a repartição de competências entre a União e as Províncias reforçaram a ideia de que entre elas não havia hierarquia, o que auxiliou à compreensão de que tais poderes, ainda que presentes no texto constitucional, não mais podiam ser exercidos (STEVENSON, 1982, p. 179). A própria legislação, no passo dessas convenções, criou mecanismo para o Governo federal consultar a Suprema Corte sobre a interpretação ou constitucionalidade de uma lei federal ou provincial, o que, para muitos comentadores do constitucionalismo canadense, foi a pá de cal naquelas competências. (STRAYER, 1988, p. 322; HEARD, 1991, p. 103 ss; ALBERT, 2014, p. 667).

As propostas de reformas federativas, por meio de emenda à Constituição, falharam no curso dos anos 1980 e início dos 1990. Tantas foram as negociações que, com o último fracasso com o 
"Acordo de Charlottetown", houve uma "fadiga constitucional" (BENZ, 2008, p. 11). Entretanto, diversas modificações foram promovidas na estrutura e, principalmente, funcionamento do Estado federal, por meio de novas rodadas de negociações entre os agentes políticos e entidades federativas. As organizações aborígenes ganharam autonomia e acesso a várias organizações intergovernamentais. A criação do "Conselho da Federação", por um acordo entre as Províncias, possibilitou maior cooperação federativa. Assim também diversas resoluções do Parlamento Federal, aprovadas em 1995 e 2006, bem como a Declaração de Calgary de 1997, assinada por todas as Províncias e Território, menos Quebec, reconheceu o Canadá como uma federação multinacional. O Estado canadense é exemplo de como as forças políticas e o Judiciário podem mudar o federalismo sem modificar o texto da Constituição. (COURCHENE, 2008, p. 3; PAPILLON, 2008, p. 308). Na Alemanha, embora com o texto constitucional bem mais recente do que o dos Estados Unidos e Canadá, foram criados diversos procedimentos e instituições de cooperação federativa, a exemplo das conferências dos presidentes dos Länder, bem como mecanismos regulamentares e financeiros de interação entre o governo central e dos Estados, fornecendo um significado e uma dinâmica ao Estado federal alemão que a frieza literal dos dispositivos não poderia prever. (HOFFMANN, 2012, p. 331-332).

No Brasil, o Estado federal caracterizadamente centrípeta, não tem um desenvolvimento adequado no nível de articulação política, basicamente, reduzida a negociações em espaços ad hoc ou puramente formais com exceções pontuais, mas ainda assim complicadas, das políticas descentralizadas de educação e saúde (ABRUCIO; FRANZESE, 2007; DUARTE; SANTOS, 2014). Ao contrário das leituras de que a Constituição havia tornado a política federal refém dos governadores (ABRUCIO, 1998), o que se vê é um predomínio da União nesses espaços e mesmo no âmbito do Senado Federal, com a prevalência de pautas relacionadas a suas macropolíticas, inclusive em detrimento de interesses concretos dos Estados. (LOUREIRO, 2001; NEIVA; SOARES, 2013). A jurisprudência do Supremo Tribunal Federal também segue a mesma tendência, orientandose por dois princípios não escritos; um, sequer expressos nas decisões; outro, vindo de longa data nos debates dos Ministros. O primeiro nem escrito nem falado se manifesta numa tendência de aplicação do postulado in dubio pro unionem, em caso de conflitos de competências entre poder central e periferia, com um leve destaque para um rebelde e impreciso interesse local, que se intercala, por vezes, no reconhecimento de atribuições municipais (SAMPAIO, 2002, p. 631 ss; $B E R C O V I C l, 2011)$. O segundo referido à polêmica "simetria" que estabelece um limite implícito ao poder constituinte decorrente. Por meio desse princípio, exige-se que a estrutura e órgãos da Constituição estadual devem reproduzir os modelos previstos na Constituição federal. Como há préordenação de quase tudo no texto federal, a aplicação desse princípio praticamente anula a esfera de autonomia de autoconstitucional dos Estados. (SAMPAIO, 2002, p. 796; LEONCY, 2011).

\section{AS DIFICULDADES NORMATIVAS DAS MUTAÇÕES CONSTITUCIONAIS}

A mudança informal da Constituição traz sérios problemas ao constitucionalismo, pois subverte a ideia de rigidez constitucional e deixa aos jogos políticos, carentes de transparência, a 
oportunidade e conveniência de serem promovidas as alterações no texto constitucional (LEVINSON, 2006, p. 164). A inexistência de um dispositivo escrito ou de referências textuais, introduzidas por esse tipo de mudança, dificulta são apenas a identificação do que mudou, mas de como ou em que bases ou a que propósitos se operou a mudança, gerando um "código constitucional informal prolixo" (STRAUSS, 2001, p. 1504; VERMEULE, 2004, p. 22) O Judiciário e os cidadãos, portanto, não têm o controle sobre o processo, criando dificuldades democráticas ou, pelo menos, uma suspeição de sua legitimidade. (DORF, 1997, p. 1780-1781).

Há, no entanto, quem defenda o processo informal como necessidade à dinâmica constitucional e federativa. A atividade atualizadora e integradora da Constituição por parte das Cortes e, principalmente, dos atores políticos responderia a demandas que, de outro modo, não seriam atendidas ou seriam de modo tardio. A Constituição lentamente de formas variadas que o processo formal é incapaz de captar (FRIEDMAN; SMITH, 1998, p. 31) ${ }^{10}$. Eventual déficit de legitimidade processual, decorrente do desvio das normas constitucionais que regulam o processo, seria compensada pela legitimidade política do processo informal, de articulação e percepção dos agentes políticos (ALBERT, 2014, p. 684) ou por uma adequada atuação judicial que atualizaria, sem sobressaltos e delongas do processo político formal, o significado de normas (LUTZ, 1994, p. 364). A indecidibilidade formal, no sentido tanto de uma atuação legislativa de emenda, quanto de uma intervenção judicial ativa, teria a virtude de mobilizar o público e os representantes populares a construírem alternativas que dinamizariam o sentido constitucional, sem comprometer o símbolo da sua escritura e a força de sua normatividade (SUNSTEIN, 1999, p. 3-4). Uma mobilização que leva a experimentações pela sociedade e à diversidade política permite escolhas muito mais adaptáveis aos câmbios sociais e políticos, sem passar por um processo complicado de alteração do texto, cuja eventual falha gera ônus práticos adicionais como déficit de normatividade e renovado esforço para correção. (WHITTINGTON, 2002, p. 791). Seria exatamente esse processo dialógico que envolve mobilização popular e debate interinstitucional que conferiria não apenas a legitimação necessária, mas uma possibilidade maior de eficácia normativa da mudança (ESKRIDGE JR.; FEREJOHN, 2001, p. 1276; GERKEN, 2007, p. 934-935). É preciso, ademais, considerar, pragmaticamente, que nenhuma Constituição escrita, por mais extensa que seja, é capaz de regular todo processo político, havendo sempre um espaço para convenções não escritas e atuação judicial que a complementam, integram e até, silenciosa e subrepticiamente, a subvertem (WHEARE, 1966, p. 15; FRIEDRICH, 1968, p. 318; FOLEY, 2011, p. 6-7). Há benefícios adicionais ao federalismo pelas mutações constitucionais.

Os Estados federais, como sistemas complexos, seriam vulneráveis ao colapso rápido, que pode ser desencadeado por mudanças constitucionais formais. A emenda constitucional informal, diferentemente, permitiria que o sistema fizesse uma espécie de "backup", que possibilitaria a recuperação do modelo original ou anterior, sempre que houvesse uma ultrapassagem dos limites entre a adaptação e o colapso, por exemplo, a destruição de um dos níveis de governo. (BEDNAR,

\footnotetext{
${ }^{10}$ Nem mesmo a ideia de Ackerman (1991) de democracia dualista, em que, além da rotina da vida política de um país, haveria momentos de alteração formal ou informal da Constituição, ajudaria: "The U.S. Constitution has changed slowly and incrementally in many ways that are not captured at all by Ackerman's constitutional moments." (FRIEDMAN; SMITH, 1998, p. 30-31).
} 
2010, p. 27). E isso só seria possível, porque o processo informal se opera, como visto, por meio de experimentações, viabilizadas pela ambiguidade do texto constitucional, que passam por um filtro de aceitação mais ponderada e mais lenta, sem os solavancos das alterações formais. (WHITTINGTON, 2002, p. 791).

A existência de mecanismos de seleção das experiências producentes e de rejeição daquelas prejudiciais funcionaria como um sistema de salvaguardas federativas. Esses mecanismos seriam fornecidos pelo controle judicial de constitucionalidade, pelo próprio sistema estrutural do federalismo, incluindo a fragmentação e incorporação das entidades subnacionais na tomada de decisões a nível federal, que não pode ser esquecido, mesmo na dinâmica dos processos silenciosos de mudança; o sistema partidário e seu funcionamento; as relações intergovernamentais com seus mecanismos de estímulos e sanções, além, claro, da opinião pública e da participação popular. Essas salvaguardas aquilatariam as mudanças constitucionais, muitas vezes de forma implícita, e podem tanto atuar de modo sequencial como simultâneo. (BEDNAR, 2010, p. 9).

\section{CONSIDERAÇÕES FINAIS}

As Constituições formais são consideradas elemento e, ao mesmo tempo, garantia do Estado federal. É ela que assegura a participação das entidades subnacionais nos processos deliberativos federais. A sua rigidez, identificada por um processo de reforma complicado e, por vezes, subtraindo matérias da possibilidade de mudança, impede que o governo central possa unilateralmente modificar a estrutura e o funcionamento do Estado federal.

A dinâmica dos processos políticos, aliada a mudanças de valores sociais, tem promovido, especialmente nas Constituições mais longevas, alterações que não se submetem àquele processo agravado de reforma ou emenda. Não se modifica o texto constitucional, mas se the atribuem sentidos diferentes dos pensados originariamente. São as chamadas mudanças informais da Constituição ou, como é mais conhecida no Brasil, mutações constitucionais.

Nos Estados Unidos, essas mudanças têm sido responsáveis pela quase totalidade das alterações constitucionais relacionadas ao federalismo, tendo ênfase o papel interpretativo e mutagênico da Suprema Corte. Foi esse processo que levou o Estado federal altamente descentralizado e dual de 1787 a um Estado mais centralizado e medianamente cooperativo ou, no mínimo, menos competitivo a partir do New Deal. Desde o final dos anos 1980, no entanto, o chamado "novo federalismo" tem, de novo, por via informal, reduzido os espaços deferidos, anteriormente, à União. No Canadá, também se verifica uma série de modificações constitucionais que não passam pelos procedimentos previstos para reforma da Constituição. Embora a Suprema Corte tenha um papel relevante nesse processo, as convenções constitucionais atuam para renovar os sentidos constitucionais, sobre o federalismo mais especificamente, sem modificação do texto constitucional. Mesmo em Constituições mais recentes, como a Lei Fundamental de Bonn de 1949, assiste-se ao mesmo fenômeno. No Brasil, embora seja grande o número de emendas, os estudos apontam a ocorrência também do fenômeno mutagênico. 
Os problemas dessas reformas silenciosas estão tanto na flexibilidade que se imprime do ponto de vista formal à Constituição, contornando o rigor normativo das exigências para promoção de emendas ao texto; como na dispensa de participação efetiva ou, pelo menos, garantida dos entes federativos nas modificações promovidas, comprometendo um dos elementos estruturantes dos Estados federais. Há, todavia, o trabalho de concertação política com reflexos recíprocos no empenho interpretativo das cortes que poderia ser visto como justificativa de superação desses problemas. A inexistência de balizas formais e de garantias de um "devido processo de mudanças constitucionais" deixa mais sombras do que luz sobre esse processo, no entanto.

\section{REFERÊNCIAS}

ABRUCIO, Fernando L. Os Barões da Federação: Os Governadores e a Redemocratização Brasileira. São Paulo: Hucitec, 1998.

ABRUCIO, Fernando L.; FRANZESE, Cibele. Federalismo e Políticas Públicas: O Impacto das Relações Intergovernamentais no Brasil. Tópicos de economia paulista para gestores públicos, v. 1, p. 13-31, 2007.

ACKERMAN, Bruce. We the People 1: Foundations. Cambridge: Belknap Press, 1991.

ALBERT, Richard. Constitutional Disuse or Desuetude: The Case of Article V. Boston University Law Review, v. 94, p.1029-1081, 2014.

ALBERT, Richard. The Conventions of Constitutional Amendment in Canada. Osgoode Hall Law Journal, v. 53, n. 2, p. 399-441, 2016.

ANDERSON, George. Federalism: An Introduction. Oxford: Oxford University Press, 2008.

ÁVILA, Ana Paula O.; RIOS, Roger R. Mutação Constitucional e Proibição de Discriminação por Motivo de Sexo. Revista Direito e Práxis, v. 7, n. 13, p. 21-47, 2016.

BALKIN, Jack M.; LEVINSON Sanford V. Understanding the Constitutional Revolution. Virginia Law Review, v. 87, n. 6, p. 1045-1104, 2001.

BARROSO, Luis Roberto. Curso de Direito Constitucional Contemporâneo. São Paulo: Saraiva, 2009.

BEDNAR, Jenna. Nudging Federalism toward Productive Experimentation, 2010. Disponível em: <http://www-personal.umich.edu/ jbednar/WIP/rfs(3).pdf>. Acesso em: 15 mar 2017.

BEHRENDT, Christian. The Process of Constitutional Amendment in Belgium. In CONTIADES, Xenopho (ed.). Engineering Constitutional Change: A Comparative Perspective on Europe, Canada and the USA. London; New York: Routledge, p. 35-50, 2013. 
BENZ, Arthur. Unsuccessful, Reform and Successful Non-Reform - Constitutional Policy Germany and Canada. Work Paper, 2008. Disponível em: <http://bit.ly/2tK5Hq3>. Acesso em 30 jan. 2017.

BERCOVICI, Gilberto. O federalismo no Brasil e os limites da competência legislativa e administrativa: memórias da pesquisa. Revista Jurídica da Presidência, v. 10, n. 90, p. 01-18, 2011.

BRASIL. Supremo Tribunal Federal. Pleno. MS 26602/DF. Rel. Min. Eros Grau, j. 04/10/2007a. Disponível em: <http://bit.ly/2tm2KhE>. Acesso em: 04 mar. 2017.

BRASIL. Supremo Tribunal Federal. Pleno. MS 26603/DF. Rel. Min. Celso de Mello, j. 04/10/2007b. Disponível em: http://bit.ly/2s3gxG8>. Acesso em: 04 mar. 2017.

BRASIL. Supremo Tribunal Federal. Pleno. MS 26604/DF. Rel. Min. Cármen Lúcia, j. 04/10/2007c. Disponível em: <http://bit.ly/2tm7vrk>. Acesso em: 04 mar. 2017.

BRYCE, James. Studies in History and Jurisprudence. V. 2. Oxford: Clarendon Press, 1891.

BURDEAU, Georges. Droit Constitutionnel et Institutions Politiques. 6e. ed. Paris: LGDJ, 1972.

CARRÉ DE MALBERG, R. Teoría General del Estado. Trad José Lión Depetre. Mexico: Fondo de Cultura Económica, 1948 [1920].

CONLAN, Timothy J. Intergovernmental Relations in a Compound Republic: The Journey from Cooperative to Polarized Federalism. Publius: The Journal of Federalism, v. 47, n. 2, p. 171-187, 2017.

CONLAN, Timothy J.; POSNER, Paul L. American federalism in an era of Partisan polarization: the intergovernmental paradox of Obama's "New Nationalism". Publius: The Journal of Federalism, v. 46, n. 3, p. 281-307, 2016.

COURCHENE, Thomas J. Reflections on the Federal Spending Power: Practices, Principles, Perspectives, IRPP Working Paper Series no. 2008-01. Disponível em: < http://bit.ly/2taLTPo >. Acesso em 30 jan. 2017.

CRISAFULLI, Vezio. Lezioni di Diritto Costituzionale. Padova: Cedam, 1970.

DAU-LIN, Hsü. Mutación de la Constitución. Trad. Pablo Lucas Verdú; Christian Förster. Oñati: IVAP, 1998.

DIXON, Rosalind. Constitutional Amendment Rules: A Comparative Perspective. In GINSBURG, SLEPT:Tom; DIXON, Rosalind (eds.). Comparative Constitutional Law, Cheltenham: Edward

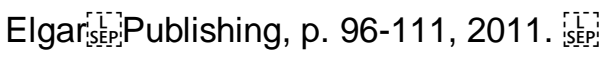

DORF, Michael C. Integrating Normative and Descriptive Constitutional Theory: The Case of Original Meaning. Georgetown Law Journal, v. 85, p. 1765-1822, 1997. 
DUARTE, Marisa RT; SANTOS, M. Rosimary Soares. Sistema nacional de educação e relações intergovernamentais no Brasil. Educação \& Sociedade, v. 35, n. 129, p. 1115-1136, 2014.

DWORKIN, Ronald. Law’s Empire. Cambridge: The Belknap Press, 1986.

DWORKIN, Ronald. Taking Rights Seriously. Londo; New York: Bloomsbury, 2013.

ESKRIDGE, William Jr.; FEREJOHN, John. Super-Statutes. Duke Law Journal, v. 50, p. 1215-1276, 2001.

ESPANHA. Tribunal Constitucional. Pleno. Sentencia 198/2012, de 6 de noviembre de 2012. Disponível em: http://bit.ly/2rNtdRF>. Acesso em 14 abr. 2017.

ESTADOS UNIDOS. Suprema Corte. Adarand Constructors, Inc. v. Peña, 515 U.S. 200 (1995). Disponível em: <http://bit.ly/2sGNYRO>. Acesso em 22 abr. 2017.

ESTADOS UNIDOS. Suprema Corte. Agostini v. Felton, 521 U.S. 203 (1997). Disponível em: $<$ http://bit.ly/2taEejL>. Acesso em 22 abr. 2017.

ESTADOS UNIDOS. Suprema Corte. Alexander v. Sandoval, 532 U.S. 275 (2001). Disponível em: <http://bit.ly/2sGNj2M>. Acesso em 22 abr. 2017.

ESTADOS UNIDOS. Suprema Corte. Board of Trustees of the University of Alabama v. Garrett, 531 U.S. 356 (2001). Disponível em: <http://bit.ly/2t7at2T>. Acesso em 22 abr. 2017.

ESTADOS UNIDOS. Suprema Corte. City of Boerne v. Flores, 521 U.S. 507 (1997). Disponível em: <http://bit.ly/2rRKGZ2>. Acesso em 22 abr. 2017.

ESTADOS UNIDOS. Suprema Corte. City of Richmond v. J.A. Croson Co., 488 U.S. 469 (1989). Disponível em: <http://bit.ly/2taJFPB>. Acesso em 22 abr. 2017.

ESTADOS UNIDOS. Suprema Corte. Miller v. Johnson, 515 U.S. 900 (1995). Disponível em: <http://bit.ly/2sGoJPo>. Acesso em 22 abr. 2017.

ESTADOS UNIDOS. Suprema Corte. Mitchell v. Helms, 530 U.S. 793 (2000). Disponível em: <http://bit.ly/2t7ekwR>. Acesso em 22 abr. 2017.

ESTADOS UNIDOS. Suprema Corte. National Federation of Independent Business v. Sebelius, 567 U.S. 519 (2012). Disponível em: <http://bit.ly/2sGKKhj>. Acesso em 22 abr. 2017.

ESTADOS UNIDOS. Suprema Corte. New York v. United States, 505 U.S. 144 (1992). Disponível em: <http://bit.ly/2s6Lhug>. Acesso em 22 abr. 2017.

ESTADOS UNIDOS. Suprema Corte. Obergefell v. Hodges, 576 U.S. _ _ (2015). Disponível em: <http://bit.ly/2sonCR3> Acesso em: 04 mar. 2017. 
ESTADOS UNIDOS. Suprema Corte. Seminole Tribe of Florida v. Florida, 517 U.S. 44 (1996). Disponível em: <http://bit.ly/2sGMTcl>. Acesso em 22 abr. 2017.

ESTADOS UNIDOS. Suprema Corte. Shaw v. Reno, 509 U.S. 630 (1993). Disponível em: $<$ http://bit.ly/2tbiYei>. Acesso em 22 abr. 2017.

ESTADOS UNIDOS. Suprema Corte. South Dakota v. Dole, 483 US 203 (1987). Disponível em: $<$ http://bit.ly/2sbUts9>. Acesso em 22 abr. 2017.

ESTADOS UNIDOS. Suprema Corte. Steward Machine Co. v. Davis, 301 U.S. 548 (1937). Disponível em: < http://bit.ly/2sTgZbo>. Acesso em 22 abr. 2017.

ESTADOS UNIDOS. Suprema Corte. United States v. Alfonso D. Lopez, Jr., 514 U.S. 549 (1995). Disponível em: <http://bit.ly/2sRmalS>. Acesso em 22 abr. 2017.

ESTADOS UNIDOS. Suprema Corte. United States v. Butler, 297 U.S. 1, 63 (1936). Disponível em: <http://bit.ly/2s6HJlc>. Acesso em 22 abr. 2017.

ESTADOS UNIDOS. Suprema Corte. United States v. Morrison, 529 U.S. 598 (2000). Disponível em: <http://bit.ly/2taxjXG>. Acesso em 22 abr. 2017.

FEREJOHN, John A.; WEINGAST, Barry R. The Politics of the New Federalism. In FEREJOHN, John A.; WEINGAST, Barry R. (eds.). New Federalism. Can the States Be Trusted? Stanford: Hoover Institution Press Publication, p. 157-164, 1997.

FERRAZ, Anna Candida da C. Processos informais de mudança da Constituição. São Paulo: Max Limonad, 1986.

FERREIRA FILHO, Manoel Gonçalves. A Constituição de 1988: Um Balanço após Dezesseis Anos de vigência. Direito Público, n. 8, p. 40-53, 2005.

FERREYRA, Raúl G. Discursos sobre Reforma Constitucional. Análisis de la Necesidad de un Nuevo Momento Constituyente para el Estado Argentino. Nomos, v. 32, n. 1, p. 213-232, 2012.

FOLEY, Michael. The Silence of Constitutions: Gaps, "Abeyances", and Political Temperament in the Maintenance of Government. 2nd. ed. London: New York: Routledge, 2011.

FRIEDMAN, Barry; SMITH, Scott B. The Sedimentary Constitution. University of Pennsylvania Law Review, v. 147, n. 1, p. 1-90, 1998.

FRIEDRICH, Carl J. Constitutions and Constitutionalism. In SILS, David L. (ed). The International Encyclopaedia of Social Science. Vol. 3. New York: MacMillan, p. 318-326, 1968.

GADAMER, Hans-Georg. Truth and Method. 2nd ed. Trad. Joel Weinsheimer; Donald G. Marshall. New York: Bloomsbury,2013 
GARGARELLA, Roberto. Dificultad, Inutilidad y Necesidad de la Reforma Constitucional. Jurisprudencia Argentina, v. 3, p. 963-967, 2004.

GERKEN, Heather K. Hydraulics of Constitutional Reform: A Skeptical Response to Our Undemocratic Constitution. Drake Law Review, v. 55, 925-943, 2007.

GRIFFIN, Stephen M. Constituent Power and Constitutional. Change in American Constitutionalism. In LOUGHLIN, Martin; WALKER, Neil (eds). The Paradox of Constitutionalism: Constituent Power and Constitutional Form. Oxford; Oxford University Press, p. 49-66, 2007.

HÄBERLE, Peter. El Estado Constitucional. Trad. Héctor Fix-Fierro. México: UNAM, 2003.

HÄBERLE, Peter. Zeit und Verfassung. Prolegomena zu einem „zeit-gerechten“ Verfassungsverständnis. Zeitschrift für Politik, v. 21, p. 111-137, 1974.

HEARD, Andrew D. Canadian Constitutional Conventions: The Marriage of Law and Politics. Toronto: Oxford University Press, 1991.

HELLER, Herman: Escritos Políticos. Trad. S. Gómez de Arteche. Madrid: Alianza, 1985.

HELLER, Herman: Teoría del Estado. Trad. L. Tobío. México: FCE, 1981.

HESSE, Konrad. Escritos de Derecho Constitucional. Madrid: Centro de Estudios Constitucionales, 1983.

HUBERFELD, Nicole; LEONARD, Elizabeth W.; OUTTERSON, Kevin. Plunging into Endless Difficulties: Medicaid and Coercion in National Federation of Independent Business v. Sebelius. Boston University Law Review, v. 93, p. 1-88, 2013.

INMAN, Robert P.; RUBINFELD, Daniel L. Rethinking federalism. The Journal of Economic Perspectives, v. 11, n. 4, p. 43-64, 1997.

JELLINEK, George. Reforma y Mutación de la Constitución. Trad. Christian Förster. Madrid: CEPC. 1991.

KAHN, Ronald. The Commerce Clause and Executive Power: Exploring Nascent Individual Rights in National Federation of Independent Business v. Sebelius. Maryland Law Review, v. 73, p. 133-186, 2013.

KORIOTH, Stefan. The Shattering of Methods in the Late Wilhelmine Germany - Introduction. In JACOBSON, Artur J.; SCHLINK, Bernhard. Weimar: A Jurisprudence of Crisis. Trad. Belinda Cooper. Berkeley: University of California, p. 41-50 2000.

LABAND, Paul. Die Wandlungen der Deutschen Reichverfassung. Jahrbuch der Gehe-Stitung zu Dresen, p. 149-186, 1895. 
LENAERTS, Koen. Constitutionalism and the Many Faces of Federalism. American Journal of Comparative Law, v. 38, n. 2, p. 205-263, 1990.

LEONCY, Léo F. "Princípio da Simetria" e Argumento Analógico. O Uso da Analogia na Resolução de Questões Federativas sem Solução Constitucional Evidente. São Paulo: USP (tese de doutoramento), 2011.

LEVINSON, Sanford. Our Undemocratic Constitution: Where the Constitution Goes Wrong (And How We the People Can Correct It). Oxford; New York: Oxford University Press, 2006.

LOEWENSTEIN, Karl. Teoría de la Constitución. Trad. Alfredo Gallego Anabitarte. Barcelona: Ariel, 1976.

LOUREIRO, Maria R. Instituições, Política e Ajuste Fiscal: O Brasil em Perspectiva Comparada. Revista Brasileira de Ciências Sociais, v. 47, n. 16, p. 75-96, 2001.

LUHMANN, Niklas. La Costituzione come Acqusizione Evolutiva. In ZAGREBELSKY, Gustavo; PORTINARO, Pier P.; LUTHER, Jörg (a cura di). II Futuro della Costituzione. Torino: Einaudi, 1996

LUTZ, Donald S. Toward a Theory of Constitutional Amendment. The American Political Science Review, v. 88, n. 2, 355-370. 1994.

MENDES, Gilmar F. O papel do Senado Federal no controle de constitucionalidade: um caso clássico de mutação constitucional. Revista de Informação Legislativa, v. 41, n. 162, p. 149-168, 2004.

MENDES; Gilmar F.; VALE, André Rufino do. O pensamento de Peter Häberle na Jurisprudência do Supremo Tribunal Federal. Observatório da Jurisdição Constitucional, 2008/2009. Disponível em: <http://bit.ly/2tINqt5>. Acesso em 31 jan. 2017.

MEYER, Laurence H. A Terma at the Fed: An Insider's View. New York: Harper Collins, 2004.

MÜLLER, Friedrich. Discours de la Méthode Juridique. Trad. Olivier Jouanjan. Paris. Puf, 1993 NEIVA, Pedro Robson P.; SOARES, Márcia M. Senado brasileiro: Casa Federativa ou Partidária? Revista Brasileira de Ciências Sociais, v. 28, n. 81, p. 98-115, 2013.

PAPILLON, Martin. Canadian Federalism and the Emerging Mosaic of Aboriginal Multilevel Governance. In BAKVIS, Herman; SKOGSTAD, Grace (eds.). Canadian Federalism: Performance, Effectiveness, and Legitimacy. Don Mills; Ontario: Oxford University Press, p. 291-313, 2008.

PEDRA, Adriano S. Mutación Constitucional y Concreción Normativa: Como la Estructura de la Norma se Relaciona con los Cambios Informales de la Constituciós. Estudios Constitucionales, n. 2, p. 369-390, 2012.

ROBERTS, Andrew. The Politics of Constitutional Amendment in Postcommunist Europe. Constitutional Political Economy, v. 20, p. 99-117, 2009. 
RUSSELL, Peter H. Constitutional Odyssey: Can Canadians Become a Sovereign People?. 2nd. ed. Toronto: University of Toronto Press, 2004.

SAGÜES, Néstor P. Elementos de Derecho Constitucional. Tomo I. $3^{\text {a }}$ ed. act. y ampl. Buenos Aires: Astrea, 2003.

SAMPAIO, José Adércio Leite. A Constituição Reinventada pela Jurisdição Constitucional. Belo Horizonte: Del Rey, 2002.

SAMPAIO, José Adércio Leite; PINTO, João Batista Moreira. O Federalismo Ambiental na Austrália e na Índia. Veredas do Direito, Belo Horizonte, v. 12, n. 23, p. 67-89, jan./jun. 2015. Disponível em: <http://dx.doi.org/10.18623/rvd.v12i23.634>. Acesso em: 19 jul. 2017.

SAMPAIO, José Adércio Leite. Teoria da Constituição e dos Direitos Fundamentais. Belo Horizonte: Del Rey, 2013.

SARLET, Ingo W.; MARINONI, Luiz G.; MITIDIERO, Daniel. Curso de Direito Constitucional. São Paulo: Revista dos Tribunais, 2012.

SARTORI, Giovanni. Constitutionalism: A Preliminary Discussion. The American Political Science Review, v. 56, n. 4, p. 853-864, 1962.

SCELLES, Georges. Droit International public, Manuel Élémentaire (avec les textes essentiels). Paris: Domat-Montchrestien, 1944.

SCHAPIRO, Robert A. Not Old or Borrowed: The Truly New Blue Federalism. Harvard Law \& Pol'y Review, v. 3, p. 33-57, 2009.

SEGALL, Eric J. Constitutional change and the Supreme Court: the Article V Problem. Journal of Constitutional Law, v.16, n.2, p. 443-451, 2013

SMEND, Rudolf. Constitución y Derecho Constitucional. Trad. José Maria B. Pérez. Madrid: Centro de Estudios Constitucionales, Madrid, 1985

SNYDER, Jack L. From Voting to Violence: Democratization and Nationalist Conflict. New York: Norton, 2000.

STEVENSON, Garth. Unfulfilled Union: Canadian Federalism and National Unity. Toronto: Gage Publishing, 1982.

STRAUSS, David A. The Irrelevance of Constitutional Amendments. Harvard Law Review, v. 114, p. 1457-1505, 2001.

STRAUSS, David A. The Living Constitution. New York, Oxford: Oxford University Press, 2010. STRAYER, Barry L. The Canadian Constitution and the Courts. Toronto: Butterworths, 1988. 
SUNSTEIN, Cass. One Case at a Time: Judicial Minimalism on the Supreme Court. Cambridge: Harvard University Press, 1999. 3-23, 1999

TALAMINI, Eduardo. Objetivação do Controle Incidental de Constitucionalidade e Força Vinculante (ou "Devagar com o andor que o santo é de barro"). In NERY JR., Nelson; WAMBIER, Teresa Arruda A. (Coords). Aspectos Polêmicos e Atuais dos Recursos Cíveis e Assuntos Afins. São Paulo: Revista dos Tribunais, p. 135-166, 2011.

URRUTIA, Ana Victoria S. Mutación constitucional y fuerza normativa de la Constitucíon: una aproximación al origen del concepto. Revista española de derecho constitucional, v. 20, n. 58, p. 105-135, 2000.

VEGA, Pedro de. La Reforma Constitucional y la Problemática del Poder Constituyente. Madrid: Tecnos, 1985

VERDÚ, Pablo Lucas. Curso de Derecho Político. Vol. IV. Madrid: Tecnos, 1984.

VERMEULE, Adrian. Constitutional Amendments and the Constitutional Common Law. University of Chicago Public Law \& Legal Theory. Working Paper, n. 73, 2004. Disponível em: $<$ http://bit.ly/2rWb20g>. Acesso em 21 mai. 2017.

WHEARE, Kenneth C. Modern Constitution. 2nd. ed. London: Oxford University Press, 1966.

WHITTINGTON, Keith E. Constitutional Construction: Divided Powers and Constitutional Meaning. Cambridge: Harvard University Press, 1999.

WHITTINGTON, Keith E. Extrajudicial Constitutional Interpretation: Three Objections and Responses. North Carolina Law Review, v. 80, n. 3, p. 773-851, 2002.

YOUNG, Ernest A. The Constitution Outside the Constitution. Yale Law Journal, v. 117, p. 408-473, 2007.

ZAKARIA, Fareed. The Future of Freedom: Illiberal Democracy at Home and Abroad. New York: W.W. Norton, 2003.

\section{COMO CITAR ESSE DOCUMENTO:}

SAMPAIO, José Adércio Leite. Federalismo e mutações constitucionais. Revista do Direito, Santa Cruz do Sul, v. 1, n. 54, p. 20-39, jun. 2018. ISSN 1982-9957. Disponível em: <https://online.unisc.br/seer/index.php/direito/article/view/9980>. Acesso em: doi:http://dx.doi.org/10.17058/rdunisc.v1i54.9980. 